\title{
“OCUPAR-SE PARA NÃO PREOCUPAR-SE": AMIZADE, ENVELHECIMENTO E ESCRITA DE SI NA EPISTOLOGRAFIA CASCUDIANA
}

RESUMO

\section{ABSTRACT}

\section{GIUSEPPE RONCALLI PONCE LEON DE OLIVEIRA}

Universidade Federal de Campina Grande

Neste artigo, trataremos do exercício da escrita de si presente nas cartas de Luís da Câmara Cascudo, enviadas a João Lyra Filho e Oswald Lamartine de Faria. Nelas, é possivel registrar alguns aspectos da vida intelectual brasileira, no período que vai de 1966 a 1986. Pretendemos entreolhar facetas da biografia intelectual de Câmara Cascudo, referentes às memórias de toda uma vida dedicada ao ensino na cidade de Natal, RN; dos livros, artigos, temas e projetos editoriais da maturidade; do envelhecimento e suas limitações, além da glória referente ao sucesso do renome intelectual e autoral, provenientes de sua contribuição ao campo da etnografia e do folclore brasileiros.

Palavras-chave: Escrita de Si. Luís da Câmara Cascudo. Epistolografia.

\section{"KEEP ONESELF BUSY IN ORDER TO AVOID WORRIES": FRIENDSHIP, AGING AND AUTOBIOGRAPHY IN CASCUDO'S EPISTOLOGRAPHY}

This paper aims to analyze the practice of writing about oneself in Luís da Câmara Cascudo's letters sent to Thadeu Vilar de Lemos, João Lyra Filho and Oswald Lamartine de Faria. In such letters, a few aspects of Brazilian intellectual life were registered over the period 1966-1986. Having a close look at the facets of Cascudo's intellectual biography will help us understand the memories related to: a life dedicated to teaching in Natal, RN; books, papers, topics and editorial projects of his Maturity; aging and limitations, in addition to the glory of his intellectual and authorial renown, resultant of his contribution to Brazilian ethnography and folklore.

Keywords: Writing about oneself. Luís Câmara Cascudo. Epistolography. 


\section{RESUMEN “OCUPARSE PARA NO PREOCUPARSE": AMISTAD, ENVEJECIMIENTO Y ESCRITA DE SI EN LA EPISTOLOGRAFÍA CASCUDIANA}

En este artículo, trataremos del ejercicio de la escritura de sí presente en las cartas de Luís da Câmara Cascudo, enviadas a João Lyra Filho y Oswald Lamartine de Faria. En ellas, es posible registrar algunos aspectos de la vida intelectual brasileña, en el período que va de 1966 a 1986. Pretendemos entrelazar facetas de la biografía intelectual de Cámara Cascudo, referentes a las memorias de toda una vida dedicada a la enseñanza en la ciudad de Natal, RN; de los libros, artículos, temas y proyectos editoriales de la madurez; del envejecimiento y sus limitaciones, además de la gloria referente al éxito del renombre intelectual y autoral, provenientes de su contribución al campo de la etnografía y del folclore brasileños.

Palabras claves: Escritura de sí. Luís de la Cámara Cascudo. Epistolografia.

O escritor constituindo glória em sua amizade, no envio de uma missiva, no soar de um louvor. Visitado como um soberano. Exaltado como um ídolo.

- Sim. É verdade. Escrevi milhares de cartas, súplicas, pedidos, auxílios, subvenções, moedas de ouro. Mendigo por correspondência.

Não me arrendei, vendi, aluguei. Todos os golpes de ameaça e sedução, aparei-os com a pena de pato.

(CASCUDO, 1974, p. 117)

\section{Escrita de si e a correspondência ativa cascudiana publicada em livros}

A epígrafe que abre este artigo provém de um dos livros mais complexos de Luís da Câmara Cascudo - Prelúdio e Fuga do Real (1974) -, obra composta em literatura tropicalmente polifônica. Preludiando ou sendo preludiado, referenciam-se as cumplicidades entre jornalismo e literatura, paixão e crítica, erudição e coloquialismo, envolvidos em ambiência de reflexão filosofante. Suas pa- lavras são de mão dupla: confidências e interlocuções, confissões e divergências, tudo em desejável reciprocidade. Como autor que fosse ao mesmo tempo roteirista-dramaturgo-encenador-cineasta, Cascudo faz, antes de tudo, a locação mais exata e atraente para seu personagem. E, embora seja a fala atribuída a Erasmo de Roterdã (1466-1536), o protagonista aqui invocado, fiel e religiosamente, é persona ou "máscara" dele mesmo (BRITTO, 2003, p. 244-245).

Cascudo, tal qual Erasmo, foi "escritor constituindo glória em sua amizade, no envio de uma missiva, no soar de um louvor. Visitado como um soberano. Exaltado como um ídolo" (CASCUDO, 1974, p. 117) Quantas pessoas vindas dos mais variados lugares do Brasil e do mundo não subiram as escadas da casa de Câmara Cascudo, na antiga Junqueira Aires (atual Av. Câmara Cascudo), em Natal, Rio Grande do Norte, para vê-lo e ouvi-lo? Escreveu sem sombra de dúvidas "milhares de cartas, suplicas, pedidos, auxílios" (GICO, 1998, p. 70) para a elaboração de suas pesquisas e produção de todo o corpus de sua obra. 
Sendo uma importante fonte para a coleta de dados, nominava sua correspondência, em que solicitava informações de pesquisa aos amigos e colegas pesquisadores e instituições, de "inquéritos diretos", "cartas perguntadeiras" e correspondência precatória, como por fim consagrou chamá-las. Enquanto suas cadernetas de notas guardavam anotações pessoais, as cartas eram textos sempre destinados aos outros. As cartas, para Cascudo, constituíam uma maneira de mostrar-se a si próprio, como fez em tantas passagens de sua obra. A escrita de si, que particularizou em especial, suas memórias nos livros $O$ Tempo e Eu, Ontem, Na Ronda do Tempo e Manual do Doente Aprendiz (GICO, 1998, p. 70; OLIVEIRA, 2009, p. 23-45).

Sendo assim, a correspondência precatória tanto fala do cotidiano particular e da família, quanto da produção de sua obra. Neste caso, solicitava abertamente tudo que precisava para escrever seus livros, e não estava ao alcance "geográfico": informações de bibliotecas, arquivos, museus, dados de família e profissionais dos estudiosos que estava referenciando e até mesmo coleta de dados de campo eram pedidos, e the vinham por correspondência das "vítimas indefesas", como costumava apelidar amigos escolhidos em Estados brasileiros ou em pontos estratégicos do exterior para fornecerem-lhe tais informações. Detalhava os pedidos, orientando o levantamento de dados, e indicando as minúcias que desejava para cada assunto com que estava ocupado. Também compunham essa correspondência dificuldades, dúvidas e estágios de desenvolvimento dos assuntos que vinha estudando (MELO, 1989, p. 16-17).

Desse modo, suas missivas eram um veículo singular de disseminação, da informação, divulgação e recebimento de notícias editoriais, já que, ele próprio, estava tão distante dos ciclos mais ativos das discussões em voga neste campo, não admitindo a falta de compromisso para "responder cartas" e manifestava publicamente sua opinião, como fez em sua coluna Acta Diurna do jornal A República, em julho de 1943 (GICO, 1998, p. 70-71):

Um dos nossos hábitos comodistas é não responder cartas ou retardar indefinidamente a satisfação desse dever. Há, naturalmente, cartas que só merecem silêncio. Outras exigem o cumprimento imediato. São consultas, por exemplo, que esclarecerão dúvidas. São informações para quem está estudando um assunto. Raramente, muito raramente, registo uma falta de resposta. Houve, entretanto, anos passados, um episódio digno de registo. Estava eu escrevendo O MARQUÊS DE OLINDA E SEU TEMPO, que a 'Brasiliana' de S. Paulo publicou. Ia juntando documentos, adquirindo livros, forjando o ambiente, sem bibliotecas e arquivos. Numa manhã registei quatro cartas. Uma para o Prefeito de Polícia de Paris, mr. Chiappe.

Outra para o Príncipe Max de Saxe, professor na Universidade de Basiléia. Outra para o prof. Fezas Vidal, Reitor da Universidade de Coimbra. A última, para o Rio de Janeiro, era a mais próxima e mais fácil. Tratava-se de um exemplar de uma publicação oficial, comprada, dada ou emprestada. 0 destinatário, grande político, uma tradição de polidez e de inteligência, compreenderia tudo. Recebi respostas da Suiça, da França e de Portugal. Recebi quanto pedira, relatório, notas, cópias autenticadas, com frases amáveis e cativantes. Do meu patrício brasileiro, o político amabilíssimo, nunca chegou às mãos uma linha siquer. Não espero mais porque ele morreu. Está perdoado e creio que Deus fez o mesmo para com su'alma [...]. (CASCUDO, 1943, p. 8)

O agenciamento de fontes primárias ou secundárias para a investigação histórica adquire sua condição por meio de um ato significativo, o de quem a preserva para o futuro, tanto quanto o de quem a recupera para o presente: é um construto, como narração ou as explicações teóricas o são. Tem a seu favor, porém, uma vantagem - sua materialidade, que lhe garante um núcleo estável, mesmo que a seu 
redor gravitem interesses ou no seu próprio cerne estes tenham se entranhado (BORDINI, 2005, p. 19).

Dessas práticas de arquivamento do eu, destaca-se o que poderíamos chamar uma intenção autobiográfica. Em outras palavras, o caráter normativo e o processo de objetivação e de sujeição, que poderiam aparecer a princípio, cedem na verdade o lugar a um movimento de subjetivação. Das cartas que recebemos, jogamos algumas diretamente no lixo, outras são conservadas durante certo tempo, outras enfim são guardadas; com o passar do tempo, muitas vezes fazemos uma nova triagem. O mesmo acontece com as de nossa autoria: guardamos cópia de algumas, seja em razão do seu conteúdo, seja em razão do seu destinatário (ARTIÈRES, 1998, p. 10).

As cartas de Cascudo que foram editadas, envolvem relações de amizades e mais espaços para tratar de assuntos culturais em termos gerais. Neste artigo, enfocaremos as obras que tratam da correspondência com os amigos: João Lyra Filho ${ }^{1}$ e Oswaldo Lamartine de Faria; nelas, é possivel registrar alguns aspectos da vida intelectual brasileira no período que vai de 1966 a 1986. Através do uso da metodologia da escrita de si (FOUCAULT, 1992; GOMES, 2004;

1 João Lyra Filho (1906-1988), jurista, financista, memorialista, biógrafo, epistológrafo, orador e professor, jornalista, poeta, contista e sociólogo, nasceu na atual cidade de João Pessoa, PB. Faleceu no Rio de Janeiro. Exerceu cargos na administração do Estado da Guanabara, atual Estado do Rio de Janeiro; entre estes: Secretário de Finanças do antigo Distrito Federal, ministro do tribunal de Contas do Estado da Guanabara e Reitor da Universidade do mesmo Estado, atual UERJ. (SILVA, 2005, p. 173-176)

2 Oswaldo Lamartine de Faria (1919-2007), sertanista, agrônomo e escritor, reconhecido o maior sertanista brasileiro por Raquel de Queiroz e Ariano Suassuna. Era detentor da cadeira de número 22 da Academia Norte-rio-grandense de Letras e autor de importantes obras da literatura potiguar. Formou-se técnico agrícola pela Escola Superior de Agricultura de Lavras, em Minas Gerais, e administrou fazendas no interior do Rio Grande do Norte, Rio de Janeiro e Maranhão. Foi técnico do Banco do Nordeste, professor da Escola Doméstica e da Escola Agrícola de Jundiaí - UFRN. (CASTRO, 2015)
IONTA, 2007; 2011; 2013), pretendemos entreolhar outras facetas da biografia intelectual de Câmara Cascudo; referentes às memórias de toda uma vida dedicada ao ensino na cidade de Natal, RN; dos livros, artigos, temas e projetos editoriais da maturidade; do envelhecimento e suas limitações, além da glória referente ao sucesso do renome intelectual e autoral, principalmente pela contribuição ao campo da etnografia e do folclore. Mas simplesmente por sua necessidade de "ocupar-se para não preocupar-se".

\section{"Como tenho a doutrina de transmitir as notícias jasmins e esquecer as xique-xique, levo essas às suas futuramente venerandas orelhas": cartas de Cascudo a João Lyra Filho}

Pobre, sem dividas, sem nadíssima solicitar, preciso ocupar-me para não preocupar-me. (CC, 29-III-1972, apud CASCUDO, 2005, p. 64)

Enfim, João-querido, ocupação para as minhas horas que não se aposentaram como eu. (CC, 30-XII-1972, apud CASCUDO, 2005, p. 79)

Os documentos analisados a partir de agora compõem a obra Flama Serena: Cartas de Luís da Câmara Cascudo a João Lyra Filho (2005); já foram catalogados, anotados e publicados resumidamente em 2000, na obra Jasmins do Sobradinho, organizados por Roberto da Silva. Conforme registrou na publicação precedente, localizou-os no arquivo do escritor João Lyra Filho, no Rio de Janeiro, em 1998. O organizador tomou conhecimento de sua existência por intermédio do destinatário das missivas cascudianas, a quem sugeriu sua divulgação. Cronologicamente, o primeiro desses documentos é uma carta sem indicação de local e data; mas, a partir de alguns dados nela contidos, depreende-se que teria sido elabo- 
rada em 1969. Considerando a intensa produção intelectual desses escritores, bem como o apreço de ambos pela epistolografia, parece incompreensivel que a correspondência entre os mesmos se tenha iniciado tão tardiamente: Cascudo estava com 71 anos e João Lyra Filho com 63 (SILVA, 2005, p. 17; 25).

Um fato biográfico de Cascudo não deve aqui ser negligenciado: sua viagem ao Rio, naquele ano. Ali, esteve de dez a vinte e sete de janeiro, e esse assunto foi amplamente anunciado pela imprensa carioca. Reencontrou familiares, velhos amigos e confrades. Ao Museu da Imagem e do Som, deu um longo depoimento; a Academia Brasileira de Letras, o Instituto Nacional do Livro, o centro Norte-Rio-grandense do Rio de Janeiro e a Campanha de Defesa do Folclore Brasileiro prestaram-lhe homenagens, distintamente. É possivel que entre Cascudo e João Lyra FiIho, então Reitor da Universidade do Estado da Guanabara, tenha havido algum contato, embora o missivista não tenha a ele se referido em Na Ronda do Tempo (Diário de 1969) e, talvez, a partir daí, uma amizade que vinha de longe, nascida com seus ancestrais, ${ }^{3}$ se tenha estreitado, e os dois escritores tenham

3 Na carta em questão, podemos ver: "Sou casado a 40 anos, com uma Dahlia, a filha mais nova (e mais bonita) do Dr. Teotonio Freire, desembargador, Juiz Federal. Da amizade de LUIS LYRA, o melhor conservador da Cidade, e das Lyras, Dondon, Alice e Adelia, amigas de minha Mãe" [...] (CC, s/d, s/l apud CASCUDO, 2005, p. 35). Diz respeito ao Des. Luís Tavares de Lyra, que foi tio de João Lyra Filho e influência decisiva em sua formação intelectual, bem como em sua conduta na administração pública (CC, s/d, s/l apud CASCUDO, 2005, p. 175). Tavares de Lyra sucedeu o governo de Pedro Velho, mas não chegou a completar o mandato, para assumir pastas ministeriais no Governo de Afonso Pena, depois no de Venceslau Brás. Era também um intelectual, possuindo uma vocação extraordinária para historiador, além de se dedicar aos estudos sociológicos e econômicos sobre o Estado do Rio Grande do Norte (SANTOS, 2009, p. 99). Em outras cartas, de 11-II-1972 e 20-III-1972, Cascudo fala sobre o centenário de Tavares de Lyra, além de disponibilizar para apreciação de João Lyra Filho, o artigo "Lyra Estadual", que no mesmo ano irá compor com outros textos o seu quarto livro de memória: Ontem (1998b). (Cf. CASCUDO, 1998b, p. 185-186) passado a cartear-se (CASCUDO, 1998a, p. 3867; SILVA, 2005, p. 24).

Nessa correspondência a João Lyra Filho, vemos que, do final de 1976 ao início de 1977, temos menção a um projeto inacabado. Tratase de um estudo sobre superstição, cujo título irá variar de Antologia da superstição no Brasil para Geografia da superstição no Brasil. Num total de oito cartas, um cartão e um telegrama enviados ao amigo, Cascudo irá convencê-lo de contribuir com o envio de um artigo para compor a obra, chega inclusive a agradecer a contribuição de Lyra Filho, todavia, a obra não chegou a ser publicada.

Esse projeto começa a ser anunciado em carta de quinze de outubro de 1976; nesta, volta a comentar sobre a necessidade de sempre continuar pesquisando, por acreditar que a "indolência é uma enfermidade irritante jamais dolce". Depois de muita promessa ao Divino Espírito Santo, ficara atuado e estava "trabucando" um cartapácio Antologia da superstição no Brasil. Iria explorar o que tinha feito ${ }^{4}$ e o que os outros iriam fazer sacrificando em louvor da deusa Amizade. Nesse projeto, excluiria as lendas religiosas e os mitos de assombro, com entidades sobrenaturais de forma humana ou bestial. Interessava-lhe nessa ocasião a superstição moente, comum, corrente, geral e pessoal. Processo instintivo secular de atrair o bem e evitar o mal, decifrar os bons e os maus agouros etc. Feita a apresentação da proposta, estende o convite:

Sonho de várias noites de verão é conseguir seduzir JOÃO LYRA FILHO para aceitar a Capitania da Paraíba, fixando n'algumas folhas de papel as SUPERSTIÇÕES DA PARAÍBA, sem muito cuidar de explicações, analises e o mais que dos autos constem. Seria uma garantia de limpidez, segurança, honestidade testemunhal, o seu depoimento, ansiosamente solicitado. Dilação proba-

4 Para um aprofundamento do tema superstição na obra de Câmara Cascudo, Cf. Lima (2003); Siqueira (2003) e Oliveira (2009). 
tória até finais de janeiro próximo. Então? Diga que sim e a noite iluminar-se-á. Ficarei álacre e buliçoso como pinto em beira de cerca. (CC, 15X-1976, CASCUDO, 2005, p. 128-129)

Em carta de vinte de outubro de 1976, Cascudo menciona que depois de enviada a carta anterior, ficou "mastigando outra missão", mais importante, rara e sugestiva que tratar das superstições paraibanas, e de enviar algumas páginas inéditas que mais valorizariam o projeto:

SUPERSTIÇÃO NO FUTEBOL ${ }^{5}$ Toque reunir ás reminiscencias e bata-língua com os antigos craques que já não pisam no gramado. Em prazo de três meses, Vossa Magnificiencia teria 'cancha' para revelações maravilhosas. Assunto virgem, donzelil, cabeçudo. V. faria as superstições paraibanas em duas semanas, máximas teria campo para desenvolver jogo na Superstição no Futebol que toda gente, $99 \%$, ignora como o caminho do Paraíso. Se V. acha não ter costado para agoentar as duas caçambas, vá arriando uma, e corra ao FUTEBOL onde é sem suplente. Fique com as duas, porque Superstição na $\mathrm{Pa}-$ raiba é carga maneira para seus ombros robustos e afeitos ao pêso-pesado. Responda, criatura de Nossa Senhora das Neves. Nem lhe digo da minha alvoroçada alegria. (CC, 20-X-1976, CASCUDO, 2005, p. 130)

No dia seis de novembro de 1976, temos um cartão de visita, escrito à mão, sem assinatura, e uma carta, que tratam, além de outros assuntos, da tentativa de convencimento de Lyra Filho a participar do processo editorial em questão. Constatamos que Cascudo contaria até o momento com 14 "promessas" de colaboração, embora não aponte quem seriam os demais nomes; ele ainda espera contar com mais 7 amigos, um deles, sendo, portanto, o

5 Cascudo sugeriu a temática, devido ao fato de João Lyra Filho ter sido presidente do Clube Botafogo de Futebol e Regatas, e do Conselho Nacional de Desportos, além de autor da maioria dos textos da legislação desportiva brasileira, tendo também institucionalizado a Justiça Desportiva no país, através de preceitos normativos do tempo em que presidiu o CND. (CASCUDO, 2005, p. 176) destinatário em questão. Cascudo, na busca de convencer o amigo, informa que tendo o original de Superstição do futebol, o livro seria um "tiro na mosca", uma grande contribuição, espécie de "Arvore do Natal ou presente dos Reis Magos" (CC, 6-XI-1976, CASCUDO, 2005, p. 132133). Em carta enviada no dia onze de dezembro do mesmo ano, percebe-se que ele conseguiu convencer João Lyra Filho a participar (CC, 11-XII-1976, CASCUDO, 2005, p. 135). Como podemos perceber, o projeto de publicação Geografia da superstição encheu-lhe a alma de preocupações deleitosas, junto ao amigo João Lyra Filho. "Esta foi a solução para não ver a 'noite' lenta, sinistra, inafastável dos mortais" (CC, 16-XII-1976, CASCUDO, 2005, p. 137).

Afora esse projeto não concluído, temos, nas cartas enviadas a João Lyra Filho, a informação de algumas das obras publicadas durante a época que a respectiva epistolografia cobre. Em trinta e um de maio de 1971, informava que "60 anos de paladar sacarino e convivência bagaceiral", Sociologia do Açúcar já estava no prelo (CC, 31-V-1971, CASCUDO, 2005 , p. 51). Aponta em carta de vinte e nove de março de 1972 que, para a elaboração da respectiva obra, contou com o conhecimento íntimo de ex-escravos da bagaceira. Os mesmos que já o tinham auxiliado com informações para a elaboração do capítulo "Comida de Escravos" na História da Alimentação no Brasil. Como estava de "guela aberta, [confidenciou] dizendo que a Fundação José Augusto publicará um livro lento e valente, Prelúdio e Fuga do Real", pede ao amigo que sente e que continuasse a ler. Havia entregado em novembro "um cartapácio de 445 páginas sobre Uma História da Assembléia Legislativa do Rio Grande do Norte". Finaliza a missiva dizendo que respondia imediatamente, porque ia "ficar uns dias debaixo d'água com um ensaio sobre a Independência no Rio Grande do Norte, convite do Governo que aceitei hoje 
e que V. é o confidente e vitima resignada" (CC, 29-III-1972, I, CASCUDO, 2005, p. 64).

Confessou ao velho amigo, em carta de dez de janeiro de 1972, que estava na idade e fase de maturação tranquila, onde os anos vividos possibilitavam esforço com os músculos pessoais. Pois a elaboração de um livro novo desarrumava a mobília interior, a disposição da nova paisagem íntima. Sendo esta resultado de raciocínio velho, experiência, prova intuição, onde os livros consultados servem só para fundamentar o ponto de vista. Tinha pavor dos livros feitos de camadas eruditas sobrepostas, sem o cimento da ideia individual e original (CC, 10-I-1972, CASCUDO, 2005, p. 82). É o que se percebe quando na respectiva correspondência faz menção aos textos clássicos e contemporâneos na correspondência em questão.

Muitos dos documentos analisados trazem a afirmação do ilimitado amor de Cascudo ao trabalho. Por isso, afirmava: “Que alegria nos dá o trabalho! Por isso pedirei a Deus uma tarefa no Paraíso, livrando-me do repouso eterno [...]" (CC, 14-XII-1973, CASCUDO, 2005, p. 99). Os raros momentos de abatimento do etnógrafo, um homem cujo bom humor era notável em suas cartas, são resultantes, justamente, da precariedade de sua saúde, que o impedia de prosseguir o incansável labor:

A saúde tem sido combustivel apenas suficiente ao trafego comum dentro de casa. Equilibro a omissão fazendo planos irrealizáveis mas uteis para utilizar o saldo imaginativo, teimoso em sublimação inconsistente. [...] A deliberada ignorância livra-me dos assombros jornalísticos, reforçando-me no tempo em que percebia confidencias de grilos e conversas de largatixas concordantes. [...] De papo em papo, a galinha enche o grão. Pretexto de matar o tempo enquanto ele não nos sepulta. (CC, 21-I-1975, CASCUDO, 2005, p. 109)

Numa das últimas cartas enviadas a João Lyra Filho, escrita em doze de maio de 1979, comenta que, em dezembro de 1978, come- morou-se a data dos seus 80 anos. Em vinte e um de abril de 1979, festejaram suas bodas de ouro, em nove de maio passou o dia pensando que, há 80 anos, fora batizado pelo Padre João Maria, ${ }^{6}$ canonizado pela cidade. Expõe que uma pilha de emoções fazia desmoronar seu equilíbrio orgânico. 0 antigo jorro epistolar estreitava-se a conta-gotas. Os olhos anoiteciam, melancolicamente, já não deixava o sobradinho da Junqueira Aires, temeroso do trânsito. Finda a carta pedindo ao amigo que maldissesse as enfermidades que lhe assaltavam, pois se sentia humilhado por não responder cartas e agradecer livros na presteza dos tempos idos. Já não mais escrevia novidades, apenas "temperava segundas edições". Serenamente, "descia a ladeira oitentona" (CC, 12V-1979, CASCUDO, 2005, p. 161).

As cartas, como documentos/monumentos, não são apenas objetos-lembranças dos elos entre amigos; são também documentos literários dotados de uma escritura peculiar. Trata-se de um gênero narrativo que guarda uma escrita de si, do sujeito e seu texto, bem como sua interação com o outro (IONTA, 2013, p. 166). A carta, texto por definição destinado a outrem, dá também lugar ao exercício pessoal, pois, quando escrevemos, lemos o que vamos escrever exatamente do mesmo modo como ao dizermos qualquer coisa, ouvimos o que estamos a dizer. A carta enviada atua, em virtude do próprio gesto da escrita, sobre aquele que envia, assim como atua, pela leitura e a releitura, sobre aquele que a recebe.

A carta que é enviada para auxiliar seu correspondente - aconselhá-lo, exortá-lo, admoestá-lo, consolá-lo - constitui, para o escri-

6 Pe. João Maria Cavalcanti de Brito (1848-1905), norte -rio-grandense. Ordenou-se no Ceará (1871). Foi vigário em algumas paróquias do interior e de Natal, onde tomou posse da freguesia em 1881. Incansável, extremamente caridoso, foi considerado santo em vida pelos paroquianos. Seu busto em bronze, inaugurado na praça do seu nome, no centro de Natal em 1921, é lugar de devoção popular, onde se reza e se acendem velas votivas. (CASCUDO, 2005, p. 162) 
tor, uma maneira de se treinar: tal como os soldados se exercitam no manejo das armas em tempos de paz, também os conselhos que são dados aos outros na medida da urgência da situação, constituem uma maneira de se preparar a si próprio para eventualidade semelhante. É algo mais do que um adestramento de si próprio pela escrita, por intermédio dos conselhos e opiniões que se dão ao outro: ela constitui também uma forma de cada um se manifestar a si próprio e aos outros. A carta faz o escritor "presente" àquele a quem a dirige, escrever é, pois "mostrar-se", dar-se a ver, fazer aparecer o rosto próprio junto ao outro. E deve-se entender por tal que a carta é simultaneamente um olhar que se volve para o destinatário (por meio da missiva que recebe, ele se sente olhado) e uma maneira de o remetente se oferecer a seu olhar pelo que de si mesmo diz (FOUCAULT, 1992, p. 145-150).

\section{"Um bom abraço deste seu velho": cartas de Cascudo para Oswald Lamartine}

Preciso ocupar-me para não preocupar-me. Não tenho Inveja e menor recalque justamente por viver com o focinho atolado nas minhas laboriosas inutilidades. Não atino com o santo do dia nem pelo nome do vigário. Encanto, Oswaldinho! (CC, 10-I-1972 apud LAMARTINE DE FARIA, 2005, p. 20)

Cartas fixam experiências. 0 tempo, sempre inevitável, desgasta - ou fortalece - relações, afetos, amizades. As cartas revelam o quanto se esteve seduzido, cativado, encantado - ou não. No caso de Oswaldo Lamartine e Luís da Câmara Cascudo, a sedução é mútua. Ambos se queriam, necessitavam-se. Cascudo, sempre urbano, estava atento ao "registrador das coisas do sertão" que Oswaldo se tornara - e o incentivava a seguir seu caminho. Oswaldo, mesmo já morando no Rio de Janeiro, metró- pole e capital cultural do país, precisava da sabedoria primordial do mestre (CASTRO, 2015, p. 104).

No texto que abre o livro, Oswaldo rememora a amizade da sua família com a família de Cascudo e as visitas do extrovertido Francisco Cascudo (1863-1935) - "era um conversador de encher a sala" - e do seu filho Câmara Cascudo a seu pai, Juvenal Lamartine, na casa da rua Trairi, 558: "Mais ou menos por esse tempo o filho dele, Cascudinho, também andava sempre lá por casa numa inquisição de perguntar a meu pai coisa do sertão velho". Estas são lembranças de quem à época "era ainda um menino para quem o mundo se resumiu num quintal de mangueiras, futebol de bola-de-meia e batalhas aéreas de arraias de rabos faiscantes de rucegas, ali bem perto do Campo do Triângulo, onde hoje construíram o Ateneu". Mesmo com os infortúnios que o destino reservou para os Lamartine nos anos 1930 - "Meu pai desterrado, nossa casa depredada e eu, sem ter condições de estudar em Natal" -, a amizade entre as duas famílias permaneceu. A década de 1940 traz Oswaldo de volta ao Rio Grande do Norte - formado pela Escola Superior de Agricultura de Lavras, irá trabalhar na Fazenda Lagoa Nova, em Riachuelo - e ao convívio de Luís da Câmara Cascudo. A amizade de "Cascudinho" com Juvenal Lamartine se estenderá, incondicionalmente, ao filho Oswaldo (CASTRO, 2015, p. 106):

Por esse tempo, Luís da Câmara Cascudo, o então, Cascudinho, também continuava amigo de meu pai e de meu irmão Silvino, pediatra de seus filhos. Foi não foi, quando eu ia a Natal, dava as caras na casa dele. Visita de amizade e perguntação: eu, tentando inutilmente tapar os buracos maiores de minha ignorância, e ele querendo saber cada coisa do sertão, se ainda era assim ou assado ou como se fazia agora cutucando, na faquinha-curta, minha curiosidade para o mundo onde vivia e não via. (LAMARTINE DE FARIA, 2005, p. 13) 
Nesta última parte que se inicia, vemos a recorrência de aspectos discutidos na passagem que versa sobre a correspondência de João Lyra Filho, ou seja, certo anseio frente ao envelhecimento, saúde e aposentadoria. Durante esse tempo, ainda vinha escrevendo e estudando com frequência, no entanto, não deve ter sido fácil imaginar que seu próprio corpo, outrora tão cheio de frescor e muitas vezes de sensações agradáveis, ficasse vagaroso, cansado e desajeitado (OLIVEIRA, 2009, p. 30-31).

No ano de 1974, Câmara Cascudo, comentando sua miopia e surdez, revela as "vantagens" que elas proporcionam. Sempre ocupado para não se preocupar, percebe-se o quanto Cascudo mostrava-se cético em relação aos jornais que noticiavam de forma equivocada sua perda de audição. Nessa mensagem, em que usa a imagem do menino que conserta brinquedo para se divertir, Cascudo dá a senha para dizer o porquê de sua grandiosa e extensa obra (CASTRO, 2015, p. 126):

Os jornais, amáveis nos audimetros, e mesmo uma TV sem assunto de futebol, informam que o velho professor está ouvindo muito mais do que grilo. Não posso andar de pandeiro na mão desmentindo. 0 remédio é morder a língua e suspeitar da honestidade funcional das progenitoras dos noticiaristas. Sigo trabalhando para entreter-me, como menino conserta brinquedo. Ocupado para livrar-me da preocupação. A surdez evita boato e a miopia, afastando jornais, garante o estado de inocência. (CC, 13-IV-1974 apud LAMARTINE DE FARIA, 2005, p. 34)

Sua condição de saúde, sempre complicada durante o período, fazia com que "ficasse com alergia à salinha de livros para não ver a pilha de cartas sem resposta e livros sem agradecimentos":

Estou com um desvio de circulação, entregue ás engrenagens do check-up, eletrocardiogramas, radioscopias toraxicas, medicação complicada sob a supervisão de minha mulher, doce e im- placavel. Preguiça mental invencivel e uma indolencia total de burocrata conspicuo. Tudo parado. Alergía à salinha de livros para não ver a pilha de cartas sem resposta e livros sem agradecimentos [...] Barbaridade! Não posso deixar de responder ao abôio do sobrinho querido, ecoando nos taboleiros cariocas. (CC, 10-V-1975, LAMARTINE DE FARIA, 2005, p. 35)

Por isso, sempre afirmava que precisava, por medida de higiene profilática, encher suas horas que não tinham se aposentado e pediam função realizadora; como a surdez lhe afastava da convivência, restava-lhe a alegria do trabalho silencioso e domiciliar:

Preciso, por medida de higiene profilatica, encher minhas horas que não se aposentaram e pedem função realizadora. O desvio circulatório, alterando o matabolismo basal, já não permite sair do poleiro quanto mais viajar, pesquisar. A surdês afasta-me da convivencia. Resta a alegria do trabalho silencioso, domiciliar, como abelha sem asas ou sapo sem pernas. (CC, 22-X1976, LAMARTINE DE FARIA, 2005, p. 38)

A necessidade de "ocupar-se para não preocupar-se" levou Cascudo a também convidar Lamartine a participar do "livro que estava trabucando", Geografia da superstição no Brasil, como já o fizera com João Lyra Filho. Cascudo, "de quenga na mão à porta do coração amigo pedindo colaboração", pois não poderia "construir Arca de Noé tendo unicamente Noé dentro da qual":

Estou trabucando uma GEOGRAFIA DA SUPERSTIÇÃO NO BRASIL, indo de quenga na mão à porta do coração amigo pedindo colaboração, pois não poderei construir Arca de Noé tendo unicamente Noé dentro da qual. Venho entregar ao velho sobrinho afetuoso o ramo de pensar, ruminar lembrar e escrever umas folhas sobre a SUPERSTIÇÃO NO SERIDÓ, no SERTÃO, ou que outro nome haja. Entrega em fim de Janeiro de 1977. Topa? Nada de lendas religiosas ou mitos de assombração, lubisôme, burrinha, caipora, tarará, tarará, etc. Superstição de caçadores, pescadores de açudes e rios, comboeiros, al- 
mocreves, gente de mercado e feira, agricultores, etc, etc, etc. Topa? Ficarei feliz tendo a V. por um companhero neste livreco limpo de invenção e mentira. (CC, 22-X-1976, LAMARTINE DE FARIA, 2005, p. 38-39)

Em carta de dezessete de novembro de 1976, devolvia as notas "gostosas sobre Supertições". Informava a Lamartine que não ia querer lenha para fogueira, utilizando suas buscas e rebuscas, desejava um "artiguinho" de seis a oito páginas, assinado e entregue até janeiro de 1977, considerado por Cascudo como prazo suficiente "para pensar, espremer a memória, catucar os parceiros, perguntando ao outros":

Devolvo as notas gostosas sobre Superstições. Não vou querer lenha para fogueira, utilizando suas buscas e rebuscas. Quero, perdôe a intimativa de tio-velho, artiguinho seu, 6 a 8 páginas, assinado, entregue até Janeiro de 1977. Prazo suficiente para pensar, espremer a memória, catucar os parceiros, perguntando aos outros. Tá? Para não 'dobrar os encantos' devolvo o 'material' que figurará no 'definitivo', convenientemente ajeitado no rumo do rasto. Não podia deixar a V. de banda, na hora em que arregimento os meus bandoleiros fieis. Saíu em Outubro o 'História dos nossos Gestos' em que 'labutei' seis anos. Edições Melhoramento, S. Paulo. Para não ver a Noite Imóvel que vem vindo, meto os peitos noutra tarefa. Mudar de rojão é descanso ao caminhador. (CC, 17-XI-1976, LAMARTINE DE FARIA, 2005, p. 40)

Em carta de primeiro de fevereiro de 1977, é possível ver Cascudo pedindo a Oswaldo Lamartine que mandasse "quando poder, uma notinha bio-biliografia sobre V. mesmo, para o nosso SUPERSTIÇÃO apresentar seus colaboradores ao respeitável público". Finaliza o assunto, comentando que o "livro cresce como vazante" (CC, 1-II-1977, LAMARTINE DE FARIA, 2005, p. 42). Na correspondência de Câmara Cascudo destinada a Oswaldo Lamartine, ainda é possível encontrar um último registro sobre o projeto desse livro, também comentado na correspondência enviada a João Lyra Filho; em carta despachada no dia três de março de 1978, Cascudo afirma que o livro Superstição no Brasil voou para o prelo:

SUPERSTIÇÃO NO BRASIL voôu para o prelo, quase completa, e no meio da catrevajem incluiu-se sua falação gostosa. 0 editor é o mesmo facínora da ANTOLOGIA DA ALIMENTAÇÃO NO BRASIL, prometendo o Cruzeiro do Sul mas não dá nem a Papacêia vespertina. Nada diz. Quero apenas que as minhas marrecas nadem. Açude ou lagôa. Milagre do Padre Ciço um escriba provinciano topar editor, espontâneo e amável como vendedor de sabão. Nem aprendi a procura-los, Oswaldinho! (CC, 3-III-1978, LAMARTINE DE FARIA, 2005, p. 52).

Talvez por essa passagem, Marize Lima de Castro (2015) tenha afirmado, em sua tese, que o respectivo projeto aqui comentado tenha sido "posteriormente publicado sob o título Superstição no Brasil (1985)". A autora afirma em nota que Câmara Cascudo já havia publicado, no ano de 1958, o livro Superstições e costumes: pesquisa e notas de etnografia brasileira, editado no Rio de Janeiro por Antunes \& Cia. Ltda., sendo uma edição comemorativa dos sessenta anos de idade e quarenta de escritor (CASTRO, 2015, p. 128). Entretanto, tão pouco o livro Superstições e costumes tenha sido o único livro publicado por Cascudo sobre a temática; como Superstição no Brasil trata-se da mesma proposta de Geografia da Superstição no Brasil, mesmo que essa informação esteja endossada pelo etnógrafo potiguar, na carta acima citada. ${ }^{8}$

7 Sobre o tema da superstição, Cascudo ainda publicou Anúbis e outros ensaios (1951) e Voz de Nessus (1966). Este último foi analisado no terceiro capítulo do livro Luís da Câmara Cascudo e a Invenção do Feminino na "cultura-popular-nordestina" (1938-1977). (Cf. OLIVEIRA, 2009, p. 96-108)

8 Em carta destinada a João Lyra Filho, Cascudo também se refere ao que acima discutimos: "Assinei contrato com a LCT EDITORA, a mesma da Antologia da Alimentação no Brasil, para imprimir a nossa Superstição! Já remeti a tralha dos 35 capítulos, alguns duas folhas e outros ensaios capitosos como os seus". (CC, 23-II-1978, apud, CASCUDO, 2005, p. 150) 
O livro Superstição no Brasil abarca quase tudo o que foi escrito sobre o assunto por Luís da Câmara Cascudo. Reúne Anúbis e Outros Ensaios (1951), Superstições e Costumes (1958) e Religião no Povo (1974). . É trabalho etnográfico, se entendermos a etnografia como o estudo de estabelecimento, modificações e vitalidade das culturas humanas, como a memória no tempo. Na realidade, são três livros elucidativos da cultura e da mentalidade do povo brasileiro, apreendidas nos costumes que afloram no cotidiano (CASCUDO, 2001, p. 11; SIQUEIRA, 2003, p. 270).

$\mathrm{Na}$ quarta edição do respectivo livro, Cascudo (2001, p. 11) afirmou que o critério não era apenas registrar em livro, "mas a tentativa de elucidação das origens. A imaginação não colaborou, mas os exemplos foram lidos ou vividos no ambiente em que viveu o autor"; podemos encontrar também uma carta de Cascudo, destinada a Pedro Paulo Moreira (editor da obra), carinhosamente chamado de Barão de Itatiaia. Nela, podemos ver Cascudo, em 1984, um ano antes da primeira edição, tratar de suas intenções para a publicação da obra:

Mando nota prefacial e o livro Religião no Povo, publicado pela Universidade da Paraíba, em 1974, cujo texto é matéria convergente para o nosso planejado 'Superstição no Brasil'. Submeto à sua apreciação julgadora a reunião dele aos outros dois antecedentes, constituindo um volumão compacto e valioso para leitura e consulta como não existe em nenhuma bibliografia na espécie. Se não aprovar, devolva o volume porque tenho poucos. Leia o índice e verá a unidade temática do livro. Plena liberdade em sua decisão. Um respeitoso abraço do seu devoto. Não concordando com a reunião do terceiro livro na 'Superstição no Brasil', retire no prefacial o período em que se alude a inserção (CASCUDO, 2001, p. 12).

9 Originalmente publicado com um prefácio de Umberto Nóbrega, reitor da UFPB, na época da sua primeira edição. Não consta na coletânea Superstição no Brasil.
Além deste que aqui tratamos, podemos dizer que Cascudo publicou apenas três pesquisas inéditas depois de 1975: História dos nossos gestos (1976), Antologia da alimentação no Brasil (1977), que foi iniciado em 1964, tendo sido finalizado em 1974, e o Príncipe Maximiliano no Brasil, 1815-1817 (1977), ensaios cujos originais permaneceram perdidos de 1935 a 1976 (CASCUDO, 2005, p. 110). Ao anunciar a João Lyra Filho seu novo projeto de pesquisa, ocasião em que pediu a colaboração do amigo, Cascudo menciona Antologia da Superstição no Brasil. Posteriormente, a pesquisa recebeu novo título Geografia da superstição no Brasil, e na última referência, apenas Superstição. Essa pesquisa jamais foi publicada; possivelmente, os originais tenham se extraviado, como muitos outros livros que Cascudo teve a oportunidade de produzir; como sabemos, alguns foram recuperados e publicados, outros não tiveram a mesma sorte. Entretanto, o respectivo debate, em crítica genética, serve para que pensemos a respeito da vasta capacidade e do ânimo de Cascudo em congregar a participação de muitos intelectuais, como João Lyra Filho e Oswaldo Lamartine de Faria em seus projetos intelectuais durante o período em análise.

\section{Considerações Finais}

Conforme sugeriu Durval Muniz Albuquerque Jr. (2008), a escrita epistolar de Cascudo é vivenciada como remédio:

Escrever até morrer, escrever para não morrer, escrever para evitar a morte, parece ter sido práticas significativas das vidas dos homens das elites do espaço que se instituía como Nordeste, no começo do século XX. A morte parece rondar estes homens, parece ameaçar de ruína seus corpos, suas vidas e todas as coisas e relações que compõem o cenário onde se desenrolam suas existências. (ALBUQUERQUE JR., 2008, p. 482) 
Em volta da escrivaninha, na biblioteca, nas margens de cada folha em branco que se preenchia a lápis ou a máquina, este sujeito parecia se reunir novamente, ganhar unidade, identidade, sentido e significado. 0 trabalho literário, a erudição histórica, a pesquisa etnográfica e folclórica, o texto memorialístico, o ensaio sociológico e a epistolografia passam a ser não somente uma estratégia de compreensão do mundo, das mudanças que estão acontecendo a sua volta, mas sim, um remédio para curar as feridas subjetivas e fisicas deixadas pelo envelhecimento (ALBUQUERQUE JR., 2008, p. 483).

Concluindo este artigo, tomamos como fechamento uma das proposições de Angela de Castro Gomes (2004), que demonstrou que o convívio entre intelectuais, como a leitura, é fundamental para o desenvolvimento de ideias e sensibilidades. Para escrever, pintar, compor etc., o intelectual precisa estar envolvido em um circuito de sociabilidade que, ao mesmo tempo, o situe no mundo cultural e the permita interpretar o mundo político e social de seu tempo. Por isso, afirma-se que não é tanto a condição de intelectual que desencadeia uma estratégia de sociabilidade e sim, ao contrário, a participação numa rede de contatos que demarca a específica inserção de um intelectual no mundo cultural.

Desse modo, avulta em importância a troca de correspondência, pois ela pode abarcar tanto os intelectuais reconhecidos como sociáveis quanto aqueles cuja preferência é a vida mais reclusa dos gabinetes de estudo e pesquisa. As cartas são, pois, uma prática de escrita que integra a produção de textos de muitos intelectuais, especialmente aqueles que viveram até meados do século XX. A correspondência pessoal entre intelectuais é, sobretudo nesses casos, um espaço revelador de suas ideias, projetos, opiniões, interesses e sentimentos. Uma escrita de si que constitui e reconstitui suas identidades pessoais e profissionais no decurso da troca de cartas (GOMES, 2004, p. 51-52).

\section{Referências}

ALBUQUERQUE JR., Durval Muniz de. A Escrita Como Remédio: erudição, doença e masculinidade no Nordeste do começo do século XX. In: Nos destinos de fronteira: história, espaços e identidade regional. Recife: Bagaço, 2008. p. 482- 493.

ARTIÈRES, Philippe. Arquivar a própria vida. Rio de Janeiro: CPDOC, 1998. Disponivel em: <http://www. cpdoc.fgv.br/revista/>. Acesso em: 09 abr. 2007.

BORDINI, Maria da Glória. Acervos de escritores e o descentramento da história da literatura. 0 eixo e a roda, Belo Horizonte, UFMG, v. 11, p. 15-23, 2005.

BRITTO, Jomard Muniz. Prelúdio e Fuga do Real. In: SILVA, Marcos. (Org.). Dicionário crítico Câmara Cascudo. São Paulo: Perspectiva; FFLCH/USP; FAPESP; Natal: EDUFRN; Fundação José Augusto, 2003. p. 241243.

CASCUDO, Luís da Câmara. Flama serena: cartas de Luís da Câmara Cascudo a João Lyra Filho. Organização, introdução e notas de Roberto da Silva. Natal: Sebo Vermelho, 2005.

Superstição no Brasil. 4. ed. São Paulo: Global, 2001.

Na ronda do tempo: diário de 1969. 2. ed. Natal: Editora da UFRN, 1998a.

Ontem: maginações e notas de um professor de província. 2. ed. Natal: Editora da UFRN, 1998b.

Prelúdio e fuga do real. Natal: Fundação José Augusto, 1974.

Responder cartas... A República, Natal, 7 de julho de 1943.

CASTRO, Marize Lima de. Areia sob os pés da alma: uma leitura da vida e obra de Oswaldo Lamartine de Faria. Natal: Programa de Pós-Graduação em Estudos da Linguagem, Universidade Federal do Rio 
Grande do Norte, 2015. (mimeo).

FOUCAULT, Michel. O que é um autor? Lisboa: Vega, 1992.

GICO, Vânia. Itinerário de um pensador. 200 f. 1998. Tese (Doutorado em Ciências Sociais) - Programa de Pós-Graduação em Ciências Sociais, Pontificia Universidade Católica de São Paulo, São Paulo, 1998. (mimeo).

GOMES, Angela de Castro. (Org.). Escrita de si, escrita da história. Rio de Janeiro: Fundação Getúlio Vargas, 2004.

IONTA, Marilda. Oneyda Alvarenga escreve a Mário de Andrade. Rev. IEB, São Paulo, n. 37, p. 161-180, dez. 2013.

A escrita de si como prática de uma literatura menor: cartas de Anita Malfatti a Mário de Andrade. Estudos Feministas, Florianópolis, v. 19, n. 1, p. 91-101, jan./abr. 2011.

As cores da amizade: cartas de Anita Malfatti, Oneyda Alvarenga, Henriqueta Lisboa e Mário de Andrade. São Paulo: Annablume; FAPESP, 2007.

LAMARTINE DE FARIA, Oswaldo. De Cascudo para Oswaldo. Natal: Sebo Vermelho, 2005.

LIMA, Marinalva Villar de. Voz de Nessus. In: SILVA, Marcos. (Org.). Dicionário crítico Câmara Cascudo.
São Paulo: Perspectiva; FFLCH/USP; FAPESP; Natal: EDUFRN; Fundação José Augusto, 2003. p. 303-306.

MELO, Veríssimo de. A obra folclórica de Cascudo como expressão do movimento modernista no Brasil. 2. ed. Mossoró, RN: Fundação Vingt-un Rosado, 1989.

OLIVEIRA, Giuseppe Roncalli Ponce Leon de. Luís da Câmara Cascudo e a invenção do feminino na cultura-popular-nordestina (1938-1977). Campina Grande, PB: EDUFCG, 2009.

SANTOS, Tarcísio Gurgel dos. Belle Époque na esquina: o que se passou na República das Letras Potiguar. Natal: Ed. do Autor, 2009.

SILVA, Roberto da. Introdução e Notas, In: CASCUDO, Luís da Câmara. Flama serena: cartas de Luís da Câmara Cascudo a João Lyra Filho. Organização, introdução e notas de Roberto da Silva. Natal: Sebo Vermelho, 2005.

SIQUEIRA, Sônia Aparecida. Superstições no Brasil. In: SILVA, Marcos. (Org.). Dicionário crítico Câmara Cascudo. São Paulo: Perspectiva; FFLCH/USP; FAPESP; Natal: EDUFRN; Fundação José Augusto, 2003. p. $270-276$

Recebido em: 20.07.2018 Aprovado em: 20.08.2018

Giuseppe Roncalli Ponce Leon de Oliveira é Doutor em História Social pela Faculdade de Filosofia Letras e Ciências Humanas da Universidade de São Paulo (FFLCH/USP), Mestre em Ciências Sociais e licenciado em História pela Universidade Federal de Campina Grande (UFCG). Atualmente desenvolve Estágio de Pós-Doutorado no Programa de PósGraduação em História (área de concentração: História, Cultura e Sociedade) da UFCG. Desenvolve pesquisas no campo dos estudos de gênero, cultura-popular-nordestina, correspondências, modernismo e regionalismo-tradicionalistanordestino, com ênfase nas obras de Luís da Câmara Cascudo, Mário de Andrade, Joaquim Inojosa, José Américo de Almeida e Gilberto Freyre. É membro dos grupos de pesquisa Estudos Culturais e Educação Intergeracional, Patrimonial e Ambiental na Paraíba: estudos rurais e urbanos. e-mail: giuseppedeoliveira9@gmail.com

R. Espirito Santo, 381, Liberdade, Campina Grande, PB. CEP: 58414-030. Telefone: (83) 998321493 